\title{
Recent Advances in Multiple-Stage Centrifugal Compressors
}

\section{Shaaban Abdallah*}

Department of Aerospace Engineering, University of Cincinnati, USA

Multiple-Stage compression through the use of two or more centrifugal compressors operating in series has been the approach to achieving high-pressure ratios. The complexity, inefficiency and cost of such systems are not ideal for most applications. We discuss here three recent innovations in centrifugal compressor multiple-stage systems in series. The first two are my patents, US 6,589,013 B2 [1] and US 7600961 B2 [2] and the third patent is Honeywell US7,568,883 B2 [3]. Our approach is to draw parallels between centrifugal and axial compressors flow paths and relate them to the threepatent theories. Although axial and centrifugal compressors differ in many ways, they have many characteristics in common.

The three patents have explored the advantages of the two systems to improve the efficiency of centrifugal multiple-stage systems. In both axial and centrifugal flow compressors, the flow enters axially, but then exits differently. In axial compressors the flow exits axially, while it exits radially in centrifugal compressors. In other words the flow enters and exits at about the same radius in axial compressors, while it enters at a small radius and exits at large radius in centrifugal compressors. Using that viewpoint, a centrifugal impeller could be converted to an axial compressor rotor by reducing its exit radius to be equal to the inlet radius and vice-versa.

The vision just described is used in the first patent to extend the efficient axial compressor flow path that consists of rotor-stator stages on the same shaft, to the centrifugal compressor system. In this patent two rotating rows of blades are mounted on the same impeller disk and separated by a stator blade row attached to the casing. That multiple stage system in centrifugal compressors has, in addition to the efficient axial compressor staging benefits, advantages unique to the centrifugal compressors. For example, it is beneficial to the backward facing blade impellers with increased backward curvature to improve the efficiency. Experimental studies [4] for one configuration of the patent is tested for two-phase flow of water and air validate the advantages of the proposed patent.

In the second patent US 7600961 B2, a multiple-stage in series that is not limited to two stages is developed. In this case two or more levels of rotating blades are mounted on the same disk. The flow exiting the first level in the radial direction is turned forward to enter the second level of blades in the axial direction. That process is repeated for other levels. The flow exiting the last level is then collected in a scroll enclosed by the flow turning apparatus and must pierce the apparatus surface to exit the compressor. One major advantage of this system is the multilevel compressor has a shorter rotating shaft.

The Honeywell patent modified the classical back-to-back parallel staging to a two-stage in series. That is achieved by turning the radial exit flow from the first impeller in the backward direction to enter the second impeller in the axial direction and exit in the radial direction from the second impeller. The fluid is then collected in a scroll that is enclosed by the flow turning apparatus. In order for the scroll outlet to exit the enclosure, the scroll outlet must pierce the enclosure surface. That interesting conversion of the classical parallel staging into a serial staging is limited to two stages. The multi-level compressor and the back-to-back Honeywell compressor share a lot of characteristics. In conclusion, the three multiple-stage centrifugal compressor systems are serial systems that have advantages over the classical multiple-stage system; they have a shorter compressor shaft with the advantage of cheaper bearings, and also have efficient and compact multiple-stage systems.

\section{References}

1. Abdallah AS (2003) Fluid Flow Controller, US 6,589,013 B2.

2. Abdallah AS (2007) Fluid transfer controllers having a rotor assembly with multiple sets of rotor blades arranged in proximity and about the same hub component and further having barrier components configured to form passages for routing fluid through the multiple sets of rotor blades, US 7600961 B2.

3. Arnold AD, Vrbas GD, Dullack KN, Thompson GF (2009) Turbocharger having two-stage compressor with boreles first-stage impeller, US 7,568,883 B2.

4. Matsushita, Naoki (2005) Influences of impeller diameter and diffuser blades on air-water two-phase flow performance of centrifugal pump. Turbomachinery 33: $483-489$.
*Corresponding author: Shaaban Abdallah, Department of Aerospace Engineering University of Cincinnati, USA, Tel: 513-556-3321; E-mail: shaaban.abdallah@uc.edu

Received August 17, 2013; Accepted August 18, 2013; Published August 23, 2013

Citation: Abdallah S (2013) Recent Advances in Multiple-Stage Centrifuga Compressors. Global J Technol Optim 4: e104. doi: 10.4172/1410-3217.1000e104

Copyright: (c) 2013 Abdallah S. This is an open-access article distributed under the terms of the Creative Commons Attribution License, which permits unrestricted use, distribution, and reproduction in any medium, provided the original author and source are credited. 